\title{
The Effect of Family Relationships on Technology-Assisted Supplemental Work and Work-Life Conflict among Academics
}

\author{
Kajal Kotecha \\ Wilfred Ukpere \\ Madelyn Geldenhuys \\ Department of Industrial Psychology and People Management, Faculty of Management \\ University of Johannesburg, Johannesburg, South Africa \\ E-mail: wiukpere@uj.ac.za
}

Doi:10.5901/mjss.2014.v5n10p516

\section{Abstract}

There is a rising trend in the use of Information Communication Technology (ICT) by academics to work after regular working hours. The dual nature of ICTs enhances work flexibility and also encourages academics to use ICTs to engage in supplemental work practices. The objective of this study was to investigate the effect of family relationships on technologyassisted supplemental work and Work-Life Conflict (WLC) experienced by academics in a higher education institution in South Africa. Specifically, the moderating roles of marital status and children were taken into consideration in investigating the relationship between TASW and WLC. A quantitative research approach was adopted and an online survey was used collect data. The WLC scale and the TASW scale were as well used. The sample consisted of academics from a higher education in South Africa $(n=216)$. The results of the research revealed a significant relationship between TASW and WLC. TASW is a significant predictor of WLC. Furthermore, the results revealed that marital status and children significantly moderated the relationship between TASW and WLC. This study contributes further knowledge to the emerging field of research relating to TASW in a South African context. This study also emphasises the implications of using ICTs and their potential to encourage academics to extend their working hours. In particular, this study outlines the important role of marital status and children in influencing the relationship between TASW and WLC.

Keywords: Academia, Children, Higher education institutions, Information communication technologies, Marital status, Technologyassisted supplemental work, Work-life balance, Work-life conflict

\section{Introduction}

The concept of working after regular working hours has become the norm in modern society. In general, most professions, including academia have become more demanding. This trend has consequently compelled academics to work beyond normal office hours (Currie \& Eveline, 2010; Santos \& Cabral-Cardoso, 2008). Jacobs and Winslow (2004) found that full-time assistants, associate professors or full-time professors in various faculties exceeded working 50 hours per week. Currie, Harris and Thiele's (2000) study expresses that academics have to work for about 50 to 55 hours a week in order to be completely satisfied with their work. Indeed, most of this work is performed after hours such as during evenings, weekends and on holidays (Kinman \& Jones, 2008; O'Laughlin \& Bischoff, 2005). Currie and Eveline (2010) reported that almost half of the academics in their sample accessed their work emails daily during their annual leave while a third accessed their work emails once a week. In addition, academics on study leave also accessed their work emails on a daily basis (Currie \& Eveline, 2010).

The phenomenon of using Information communication technologies (ICTs), such as laptops and smart phones, to work after regular working hours is referred to as technology-assisted supplemental work (TASW) (Fenner \& Renn, 2004). According to Currie and Eveline (2010), ICTs have indeed invaded academics' personal space and have transformed the home into a workplace for many individuals. In fact, Gornall and Salisbury (2012:141) commented that working from home was once considered a privilege for academics, but added, "perhaps there are now reasons to rethink this". There is strong consensus among researchers that ICTs are blurring the traditional boundaries between work and family (Currie \& Eveline, 2010; Boswell \& Olson-Buchanan, 2007). The fact that ICTs enable academics to easily engage in either role creates work-life conflict (WLC) (Batt \& Valcour, 2003; Heijstra \& Rafnsdottir, 2010). The flexibility enabled by ICTs and the privilege of working from home therefore raises important questions pertaining to academics' WLB (Boswell \& Olson-Buchanan, 2007). More so, engaging in TASW may have detrimental consequences on academics' family relationships. For example, academics may not be able devote sufficient time for their children and/or spouse when they use ICTs to work after hours at home. 


\subsection{Problem statement}

Academics may feel guilty for not being able to fulfil their family role, even when they are at home. However, there is also evidence that the presence of children may limit an individual from engaging in supplemental work practices. In addition, the increased responsibilities that arise from being married may also influence the extent to which individuals engage in TASW and experience WLC. Hence, the contradictory outcomes on family relationships that arise from engaging in TASW require further investigation.

\subsection{Objective of the study}

The objective of this study was to investigate the effect of family relationships on TASW and WLC experienced by academics in a higher education institution in South Africa. Specifically, the moderating roles of marital status and children were taken into consideration in investigating the relationship between TASW and WLC.

\subsection{Technology-Assisted Supplemental Work}

Prior research on supplemental work has been investigated by Venkatesh and Vitalari (1992) and Duxbury, Higgins and Thomas (1996). Supplemental work, as explained by Venkatesh and Vitalari (1992), is a form of distributed work, where full-time individuals work at home after regular working hours or on weekends. According to Fenner and Renn (2004), the concept of supplemental work is not a new phenomenon as individuals often work at home during the evenings and weekends. However, the increased possibility of being able to do so, with the support of ICTs, is regarded as a new phenomenon (Fenner \& Renn, 2004; Venkatesh \& Vitalari, 1992). Fenner and Renn (2004:179) coined the term 'technology-assisted supplemental work' (TASW), which they define as the "performance of role-prescribed job tasks by full-time employees with the aid of advanced information and telecommunications technology at home or when away from home while on holiday". An example of TASW is when an academic responds to work-related emails during evenings and/or on weekends. This form of distributed work is mainly performed by white-collar workers without any compensation agreement (Fenner \& Renn, 2010). Furthermore, TASW is dependent on technological tools such as emails, smart phones, computers and wireless devices (Fenner \& Renn, 2004). The use of these devices to work after working hours may engender work-life conflict.

\subsection{Work-Life Conflict}

According to Brough, O'Driscoll and Kalliath (2005) and Valcour (2007), one of the major challenges encountered by today's workforce is to maintain a balance between work-life and family-life. Work-Life Conflict (WLC) is a result of not being able to achieve a balance between an individual's work domain and family domain (Duxbury, Higgins \& Lee, 1994). Greenhaus and Beutell (1985:77) define WLC as "a form of inter-role conflict in which the role pressures from the work and family domains are mutually incompatible in some respect". The incompatible role pressures that arise from both domains hinder individuals' performances in other roles (Carlson, Grzywacz \& Zivnuska, 2009; Greenhaus, Allen \& Spectator, 2006). For the purposes of the current study, the researchers specifically focus on how work creates conflict in an academic's personal life (which also includes their family life).

Greenhaus and Beutell (1985) identified three main forms of WLC, namely, behavioural-based conflict, time-based conflict, and strain-based conflict. In particular, the study focuses on three dimensions, namely, behavioural-based work interference with family, time-based work interference with family, and strain-based work interference with family. Behavioural-based conflict is when certain behaviours that are necessary in one role are incompatible with the behaviours that are expected in another role (Greenhaus \& Beutell, 1985). Time-based conflict occurs when the time spent in one role (for example, work) makes it difficult to participate in another role (for example, family and/or personal relationship) (Greenhaus \& Beutell, 1985; Messersmith, 2007). Strain-based conflict is when strain experienced in one role makes it difficult and challenging to participate in another role. For example, stress experienced at work is transferred or 'spills-over' onto another role, which consequently reduces an individual's effectiveness in that role (Greenhaus \& Beutell, 1985; Greenhaus et al., 2006; Messersmith, 2007). Examples of work sources that create strain include role conflict and role ambiguity.

\subsection{TASW, WLC and Academia}

Working after hours during the evenings and weekends has become an unspoken rule and practice in the academic 
profession (Santos \& Cabral-Cardoso, 2008). Academics often work during the evenings and weekends in order to cope with the escalating work demands and work pressures (Houston, Meyer \& Paewai, 2006; Kinman \& Jones, 2008; O'Laughlin \& Bischoff, 2005). Working normal hours is associated with a 9am to $5 \mathrm{pm}$ work schedule that runs from Monday to Friday (Kinman \& Jones, 2008). In addition, Westenholz (2006) further explains that 'normal working hours' involves working for 40 hours per week and having the weekends free. However, academics in Currie et al.'s (2000) study articulate that they do not have a 9am to $5 \mathrm{pm}$ work schedule as they work 24/7. Hence, academics always have work to keep them busy which results in supplemental work practices.

Studies consistently report work flexibility to be one of the main advantages of working in academia (O'Laughlin \& Bischoff, 2005; Rafnsdottir \& Heijstra, 2011). ICTs have indeed empowered academics with more autonomy and flexibility (Araújo, 2008). Furthermore, ICTs have also consequently created additional opportunities for academics to work from home, enabling them to balance their work and family demands (Araújo, 2008; Currie \& Eveline, 2010; Rafnsdóttir \& Heijstra, 2011).

Research reveals that although ICTs enhance academics' work-life, they do however also increase academics' workloads and encourage them to further extend their working day (Currie \& Eveline, 2010; Heijstra \& Rafnsdottir, 2010). To take an example, Ylijoki and Mantyla (2003) mention that, although email enhances communication and saves time, it also nonetheless requires academics to be constantly available for students and colleagues. Many academics actually begin their day, in the early morning, checking their emails and persistently continue to do so throughout the day, even during the evenings (Gornall \& Salisbury, 2012; Heijstra \& Rafnsdottir, 2010). Academics often work during the evenings by using their Notebooks to check emails and to work on their own research projects (Gornall \& Salisbury, 2012). Furthermore, Currie and Eveline (2010) found that many academics in their study worked on their computers from 8pm to 10pm. Heijstra and Rafnsdottir (2010) reported that academics often have difficulty in detaching themselves from work when they are on family holidays. For instance, many academics feel tempted to take their laptops and cell phones with them in order to stay connected to their work. The ubiquitous connectivity facilitated by ICTs has therefore been regarded by researchers as both a "blessing and a curse" (Currie \& Eveline, 2010, p. 10; Harmer, Pauleen \& Schroeder, 2008, p. 9; Hewlett \& Luce, 2006, p. 54).

Based on the above literature, the following hypothesis has been generated:

H1: Academics within a higher education institution in South Africa use ICTs after normal working hours to engage in supplemental work practices.

\subsection{The consequences of TASW and the relationship with WLC}

The use of ICTs to engage in supplemental work after regular working hours has various positive and negative consequences on academics' work-lives. For example, a positive outcome of TASW, according to Venkatesh and Vitalari (1992), is that individuals have the ability to perform better than their colleagues as a result of having fewer work interruptions and more independence. Indeed, Gornall and Salisbury (2012) reported in their study that academics were most productive when they worked from home rather than from their institution.

However, engaging in supplemental work practices using ICTs also seems to have a negative impact on an individual's work-life as well as on his/her wellbeing. Additionally, working long hours has also been positively associated with WLC (Batt \& Valcour, 2003; Skinner \& Pocock, 2008). Kinman and Jones (2008) found that academics who worked during the evenings and on weekends experienced more WLC than academics who did not work after hours. It is therefore not surprising that studies in this field of research have suggested and found a significant relationship between TASW and WLC (Boswell \& Olson-Buchanan, 2007; Fenner \& Renn, 2010; Fenner \& Renn, 2004; Messersmith, 2007). These studies reveal a positive relationship between TASW and WLC. Hence, academics who engage in TASW are more likely to experience WLC. The reason for this, as explained by Boswell and Olson-Buchanan (2007), is that, as individuals devote more time to work at home, it becomes extremely difficult to fulfil the role requirements and demands in the non-work domain. Accordingly, academics may experience time-based WLC. In addition, psychologically, academics have to be able to disengage themselves from their family and other non-work activities so as to engage in work-related activities (Fenner \& Renn, 2004; Messersmith, 2007). Similarly, Kinman and Jones (2008) found in their study that academics often reported being preoccupied with work during non-working hours and having trouble relaxing and sleeping. This may further generate additional strain-based conflict (Messersmith, 2007). Furthermore, continuous concentration on work at home may lead academics to ignore the requirements and expectations of family members while in the non-work domain (Fenner \& Renn, 2010). Thus, working after hours, with the aid of ICTs, may further create behavioural-based WLC in addition to time- and strain-based WLC as explained previously.

Based on the above discussion, the following hypothesis was generated: 
$\mathrm{H} 2$ : There is a significant relationship between TASW and WLC among academic staff within a higher education institution in South Africa.

\subsection{Marital Status, Children, TASW and WLC}

According to Boswell and Olson-Buchanan (2007), individuals will experience lower levels of WLC if engaging in TASW is considered the norm and an accepted work practice in a certain profession. It can therefore be expected that, since working long hours has become the norm in academia, the WLC experienced by academics may not be very high. However, various studies have found that academics who engage in supplemental work practices at home still do experience higher levels of WLC (Currie \& Eveline, 2010; O'Laughlin \& Bischoff, 2005; Heijstra \& Rafnsdóttir, 2010; Rafnsdóttir \& Heijstra, 2011). In addition, Fenner and Renn (2004) suggest that time and boundary management skills mediate the relationship between TASW and WLC.

Studies have suggested that demographic factors such as gender, parental status, marital status and job position play an important role in influencing this relationship (Boswell \& Olson-Buchanan, 2007; Parasuraman \& Simmers, 2001; Venkatesh \& Vitalari, 1992). For the purposes of this study, marital status and children are taken into consideration in examining the relationship between TASW and WLC. With regard to marital status, Russell et al. (2009) reported that married couples experienced more WLC than single individuals, and that both genders experienced equally high levels of WLC as a result of having young children in their family. Contrary to this, Hamilton, Gordon and Whelan-Berry (2006) found no statistical difference in the amount of WLC experienced by both, married and unmarried individuals without children. According to Hamilton et al. (2006), unmarried individuals without children also experience a similar amount of WLC as married individuals without children even though they do not necessarily have the same family demands arising from the non-work domain. Hence, marital status seems to be an important factor in influencing the WLC experienced by individuals. Similarly, the presence of children in an academic's life also seems to play an important role in influencing the extent to which individuals experience WLC and engage in supplemental work practices due to increased responsibilities that arise from the non-work domain (Clark, 2001; Venkatesh \& Vitalari, 1992). Venkatesh and Vitalari (1992) found that the presence of children was negatively related to supplemental work at home.

Based on the above discussion, the following hypothesis has been generated:

H3: Marital status and children moderates the relationship between TASW and WLC

\section{Research Approach}

A quantitative research approach was adopted to address the research objective of this study. In particular, a crosssectional research design was used.

\section{Research Method}

\subsection{Sampling Procedure}

This study used two-non-probability sampling methods, namely purposive and convenience sampling to select academics from a higher education institution in South Africa. However, a limitation is that these sampling methods are not representative of the population and were selected based on the researchers' judgement about academia. In total, 1033 emails were sent out to academic staff to participate in the online survey. A total of $\mathbf{2 1 6}$ usable surveys were obtained after two weeks, which resulted in a response rate of $21 \%$.

\subsection{Participants}

The demographic profile of the respondents in the current study is as follows. The sample consists of 130 female respondents $(60.2 \%)$ and 85 male respondents (39.4\%). The respondents' ages vary from between 25 to 40 years $(45.8 \%)$ and from 41 to 66 years $(49.8 \%)$. Regarding the race of the respondents, the majority of sample is White $(62.7 \%)$, followed by African Black (22.1\%). Furthermore, the sample is primarily dominated by respondents who are married (67.8\%) and thereafter followed by academics who are single (19.7\%). In terms of children, $62.0 \%$ of respondents in the sample have children. Further, of the $62.0 \%$ of respondents who have children, $24.5 \%$ have two children followed by $19.4 \%$ who have one child. In addition, $70.1 \%$ of respondents do not have a dependent who is not their own child, while $29.9 \%$ have a dependent other than their own child. 
The majority of respondents' home language is English (44.8\%), followed by Afrikaans (38.4\%), Nguni (7.9\%), Sotho (7.4\%) and lastly, Venda/Tsonga (1.5\%). In terms of educational qualifications, the respondents in the sample mainly have a master's qualification (48.4\%) followed by a doctoral degree (44.6\%), honours degree (4.6\%), bachelor's degree (1.4\%), certificate/diploma (.5\%) and, lastly, matric (.5\%). Additionally, the sample primarily comprises respondents with a lecturer designation (45.2\%) followed by a senior lecturer (28.1\%), associate professor (10.5\%), professor (9.0\%), head of department (5.7\%) and, lastly, a researcher (1.0\%). The sample was screened to include only full-time academic staff. This therefore resulted in a total sample of 216 full-time academic staff (100\%). Furthermore, the majority of respondents (36.4\%) indicated that they work after hours for between 3 and 4 hours per day while $30.3 \%$ work after hours for between 1 and 2 hours per day. It should be noted that $14.0 \%$ of respondents spend 7 or more hours working at home, while $13.5 \%$ spend between 5 and 6 hours per day working after regular working hours at home. Lastly, $5.8 \%$ of respondents spend less than an hour on work-related activities after hours at home using ICTs. Furthermore, $\mathbf{8 7 . 9 \%}$ of respondents indicated that their institution provides them with a laptop or a similar ICT device for work-related purposes. A small proportion of $12.0 \%$ indicated that their institution does not provide them with ICTs for their work. Lastly, in terms of the type of ICTs used to engage in TASW, the majority of respondents (91.7\%) mainly use their laptops followed by their smartphones (48.8\%), Tablet (41.2\%) and their desktop computer (20.4\%).

\subsection{Measuring Instruments}

Demographic questions: This section provided general demographic related information about respondents participating in the study. These include the following: age, gender, race, educational qualification, marital status, home language and whether respondents have children and/or dependents. Additional questions related to academic staffs' designation, their employment type as well as the number of hours spent per day using ICTs to work after hours. Furthermore, academics were asked to indicate the type of ICT devices, which they use to engage in TASW and whether their institution provides them with any ICTs for work-related purposes.

Work-life conflict: A shortened version of 9 items in Carlson, Kacmar and Williams (2000) WLC scale was used to assess the WLC experienced by academic staff in all three forms of WLC: 1) behavioural-based work interference with family; 2) time-based work interference with family; and 3) strain-based work interference with family. Thus, the 9 items that assess each of these sub-constructs were the main focus of the current study. The items were rated on a five-point Likert scale, ranging from (1) 'strongly disagree' to (5) 'strongly agree'. The following are some examples of behavioural-, time- and strain-based work interference with family statements, respectively: "The problem-solving behaviours I use in my job are not conducive to resolving problems at home"; "My work keeps me from my family activities more than I would like"; "Due to all the pressures at work, I often come home too stressed to do the things I enjoy" (Carlson et al., 2000, p. 260).

Carlson et al. (2000) assessed the internal consistency of all six items with coefficient alpha. The results revealed that all six items are reliable with high Cronbach's alpha coefficient values of above the accepted .70 (Carlson et al., 2000).

Technology-assisted supplemental work: A recently developed TASW scale, by Fenner and Renn (2010), was used to determine whether academic staff in a higher education institution in South Africa use ICTs to work after regular working hours. The scale consists of six items which were rated on a five-point Likert scale, ranging from (1) 'never' to (5) 'always' (Fenner \& Renn, 2010). An example of an item in this scale includes: "I perform job-related tasks at home, at night, or on weekends, using my cell phone, pager, BlackBerry or computer" (Fenner \& Renn, 2010, p. 70). The five-item scale was reported as reliable with a Cronbach's coefficient alpha value of .88 (Fenner \& Renn, 2010).

\subsection{Procedure}

This research was conducted once permission was granted from the Ethics Committee and from the higher education institution. In addition, an explanatory statement was included on the first page of the online survey that explained the purpose of the study and further emphasised that participation in the online survey was voluntary and to be completed anonymously. Additionally, it was explained that all responses obtained from the online survey would be kept confidential and would not be disclosed to any third party who was not involved in the current study.

A pilot study was first conducted before formally distributing it to academic staff at the higher education institution. This was done to assess the reliability and validity of the online survey. The online survey was then launched after addressing the recommended changes from the pilot study. Following the pilot study, an email was sent out to all academic staff inviting them to participate in the research study. The email content briefly explained the rationale of the 
study and emphasised the anonymity and confidentiality of their responses. The email included the URL link to the webbased survey, which directed respondents to the online survey. The data was collected over a period of two weeks. Additionally, a reminder email was also sent a week after the initial email. Once academic staff completed the survey, their responses were anonymously and automatically recorded on the system.

\subsection{Statistical Analysis}

The data from the online survey responses was retrieved electronically by using the Statistical Package for Social Sciences (SPSS). The data was first screened and cleaned before conducting additional analyses on the data. In particular, the two negatively phrased statements in the TASW were reversed before proceeding to the analysis. Cronbach's alpha coefficients were used to assess the reliability of the constructs that were used in this study. Descriptive Statistics, such as the means, standard deviations, skewness and kurtosis were used to describe and summarise the data obtained from the online survey responses. Inferential statistics, such as correlations and multiple regressions were also used to analyse the data. Pearson's correlation coefficient was used to assess the relationship between TASW and WLC.

In addition, two separate, three-step, hierarchical multiple regression analysis was computed for WLC as a predictor; TASW as the main effect and, marital status and children as the moderators. It should be noted that for the multiple hierarchical regression analysis, the variables were centred. In the first step, the predictor variable (TASW) was entered into the regression model, the moderator (marital status, children) in the second step, followed by their interaction (for example, TASW x marital status) in the third step.

\section{Results}

\subsection{Descriptive Statistics for TASW and WLC}

Table 1 presents the means, standard deviations, skewness and kurtosis and Cronbach's alpha coefficient values of the following variables: total TASW score, total time-based WLC, total strain-based WLC, total behavioural-based WLC and total WLC score.

Table 1: Descriptive statistics and Cronbach's alpha coefficients (a) of the constructs

\begin{tabular}{lccccc}
\hline Construct & Mean & Std. Deviation & Skewness & Kurtosis & $\alpha$ \\
\hline Total TASW & 25.58 & 3.65 & -.870 & .446 & .84 \\
Total time-based WLC & 9.52 & 3.12 & -.213 & -.837 & .89 \\
Total strain-based WLC & 8.97 & 3.22 & -.033 & -.999 & .89 \\
Total behavioural-based WLC & 7.67 & 2.51 & .160 & -.296 & .82 \\
Total WLC & 26.07 & 7.14 & -.135 & -.710 & .88 \\
\hline
\end{tabular}

The total TASW score has a mean value of 25.58 and standard deviation of 3.65. This indicates that academics within this higher education institution seem to use ICTs after normal working hours to engage in supplemental work practices. Hence, hypothesis 1 is supported in the current study. Furthermore, it can be seen from Table 1 that respondents seem to experience slightly more time-based $\mathrm{WLC}(M=9.52, S D=3.12)$ followed by strain-based $W L C(M=8.97, S D=3.22)$, and, thereafter, behavioural-based WLC $(M=7.67, S D=2.51)$. The overall WLC score has a mean score of 26.07 and standard deviation of 7.14. Thus, from the mean values, academic staff members from this higher education institution seem to experience all three forms of WLC.

The internal consistency (reliability) of each scale was assessed by calculating Cronbach's alpha coefficient. This is referred to as the extent to which all items in the scale measure the same construct (Pallant, 2009). Furthermore, Nunnally $(1978$, as cited in Bernardi, 1994, p. 767) states that a Cronbach's alpha coefficient value of .7 is regarded as acceptable while values above .8 are desirable. The table presents the Cronbach's alpha coefficient values for all TASW scale and sub-scales of the WLC scale. It is evident that each of the scales has a Cronbach's Alpha Coefficient value of above .8. Thus, all the scales are highly reliable with the current study's sample as suggested by Nunnally (1978, as cited in Bernardi, 1994, p. 767). These findings are also consistent with those of Fenner and Renn's (2010) and Carlson et al. (2000) for TASW and WLC, respectively. 


\subsection{The relationship between TASW and WLC}

Table 2: The correlation between TASW and WLC

\begin{tabular}{|c|c|c|c|c|c|}
\hline Scale & 1 & 2 & 3 & 4 & 5 \\
\hline 1. Total TASW & - & & & & \\
\hline 2. Total time-based WLC & $.398 * \star$ & - & & & \\
\hline 3. Total strain-based WLC & $.250 * \star$ & $.661^{\star *}$ & - & & \\
\hline 4. Total behavioural-based WLC & -.015 & $.308^{* *}$ & $.440 \star \star$ & - & \\
\hline 5. Total WLC & $.284^{\star *}$ & $.845^{\star \star}$ & $.887^{\star \star}$ & $.671^{\star \star}$ & - \\
\hline
\end{tabular}

Table 2 shows the Pearson correlation between TASW and WLC. The Pearson correlation revealed a significant positive relationship between TASW and WLC ( $r=.28, n=193, p<.01$, two tailed). However, as suggested by Cohen, the strength of this relationship is small (1988, as cited in Pallant, 2009, p. 134). There is a small but significant relationship between TASW and WLC. On the basis of the above results, hypothesis 2 is accepted as the p-value is less than .01 . Accordingly, this indicates that the relationship between TASW and WLC is statistically significant and not as a result of chance.

Furthermore, the table also presents the relationship between TASW with each of the WLC sub-scales. There is a positive significant correlation between TASW and time-based WLC $(r=.39, n=195, p<.01)$ as well as with strainbased WLC $(r=.25, \mathrm{n}=199, p<.01)$. Hence, as academics engage in TASW, they also experience time-based and strain-based WLC. Interestingly, however, it should be noted that there is a negative relationship between TASW and behavioural-based WLC which is not significant $(r=-.15, \mathrm{n}=199, p>.01)$. With the exception of behavioural-based WLC, academics within this higher education institution in South Africa significantly experience both time-based and strain-based WLC as a result of engaging in TASW. These results further enhance the overall findings of the relationship between TASW and WLC.

Table 3: Multiple regression of WLC as the dependent variable and TASW and marital status as the independent variables

\begin{tabular}{|c|c|c|c|c|c|c|c|c|c|c|}
\hline \multirow[t]{2}{*}{ Model } & & \multicolumn{2}{|c|}{ Unstandardised Coefficient } & \multirow{2}{*}{$\frac{\text { Standardised Coefficient }}{\text { Beta }}$} & \multirow[t]{2}{*}{$\bar{t}$} & \multirow[t]{2}{*}{$P$} & \multirow[t]{2}{*}{$F$} & \multirow[t]{2}{*}{$R$} & \multirow[t]{2}{*}{$R^{2}$} & \multirow[t]{2}{*}{$\Delta R^{2}$} \\
\hline & & $B$ & $S E$ & & & & & & & \\
\hline \multirow[t]{2}{*}{1} & Constant & 11.82 & 3.52 & & 3.37 & .00 & 16.15 & .28 & .08 & .07 \\
\hline & TASW & .55 & .13 & .284 & 4.07 & $.00 *$ & & & & \\
\hline \multirow[t]{3}{*}{2} & Constant & 9.09 & 3.87 & & 2.34 & .02 & 9.76 & .31 & .09 & .08 \\
\hline & TASW & .57 & .13 & .29 & 4.18 & $.00^{*}$ & & & & \\
\hline & Marital status & 1.65 & .92 & .12 & 1.78 & .07 & & & & \\
\hline \multirow[t]{4}{*}{3} & Constant & 45.84 & 8.55 & & 5.35 & .00 & 14.80 & .44 & .19 & .18 \\
\hline & TASW & -.93 & .34 & -.48 & -2.72 & .00 & & & & \\
\hline & Marital status & 146.08 & 30.40 & 11.11 & 4.80 & $.00^{*}$ & & & & \\
\hline & TASW X Marital status & 6.76 & 1.42 & 11.08 & 4.75 & $.00 *$ & & & & \\
\hline
\end{tabular}

Table 3 shows that, in step 1, TASW accounts for $8 \%$ of the variance in WLC $\left[F_{(1,191)}=16.77 ; \beta=.28 ; p<.05\right]$. The inclusion of marital status in step 2 does not explain any variance in $\operatorname{WLC}[\Delta F(1,191)=3.17 ; \beta=.12 ; p>.05]$. This accordingly indicates that marital status is not a significant predictor of WLC. However, in the third step, the two-way interaction variable $\left[\Delta F_{(1,191)}=22.58 ; \beta=11.08 ; p<.05\right]$ reveals that marital status significantly moderates the relationship between TASW and WLC. Hypothesis 3 is therefore accepted.

Figure 1: Graph illustrating the moderating effect of marital status on TASW (main effect variable) and WLC (dependent variable)

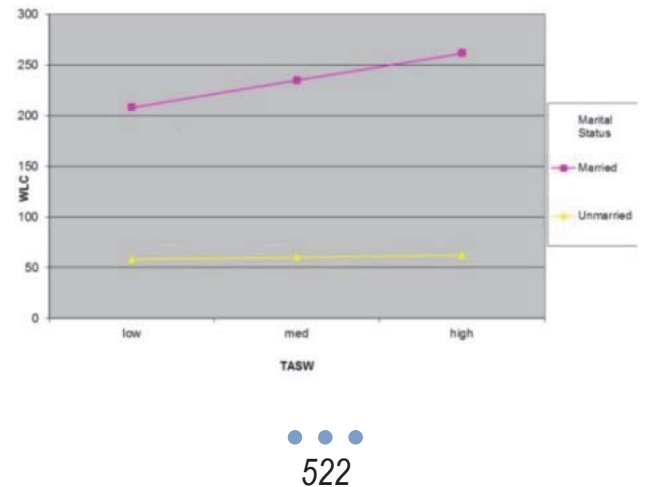


Figure 1 illustrates that married academics experience higher levels of WLC compared to unmarried academics. Further, the level of WLC of married academics increases the more they engage in TASW compared to unmarried academics.

Table 4: Multiple regression of WLC as the dependent variable and TASW and children as the independent variables

\begin{tabular}{|c|c|c|c|c|c|c|c|c|c|c|}
\hline \multirow[t]{2}{*}{ Model } & & \multicolumn{2}{|c|}{ Unstandardised Coefficient } & \multirow{2}{*}{$\frac{\text { Standardised Coefficient }}{\text { Beta }}$} & \multirow[t]{2}{*}{$t$} & \multirow[t]{2}{*}{$P$} & \multirow[t]{2}{*}{$F$} & \multirow[t]{2}{*}{$R$} & \multirow[t]{2}{*}{$R^{2}$} & \multirow[t]{2}{*}{$\Delta R^{2}$} \\
\hline & & $B$ & SE & & & & & & & \\
\hline \multirow[t]{2}{*}{1} & Constant & 12.22 & 3.43 & & 3.56 & .00 & 16.77 & .28 & .08 & .07 \\
\hline & TASW & .54 & .13 & .28 & 4.09 & $.00^{*}$ & & & & \\
\hline \multirow[t]{3}{*}{2} & Constant & 12.13 & 4.25 & & 2.85 & .00 & 7.82 & .28 & .08 & .07 \\
\hline & TASW & .55 & .14 & .28 & 3.85 & .00 & & & & \\
\hline & Children & -.12 & 1.08 & -.00 & -.11 & .90 & & & & \\
\hline \multirow[t]{4}{*}{3} & Constant & 45.02 & 11.18 & & 4.02 & $.00^{*}$ & 8.82 & .36 & .13 & .11 \\
\hline & TASW & -.74 & .43 & -.38 & -1.72 & .08 & & & & \\
\hline & Children & 111.24 & 35.18 & 7.54 & 3.16 & $.00 *$ & & & & \\
\hline & TASW $X$ Children & 5.26 & 1.66 & 7.71 & 3.16 & $.00 *$ & & & & \\
\hline
\end{tabular}

${ }^{*} p<.05$ (2-tailed)

Table 4 shows that in step 1, TASW accounts for $8 \%$ of the variance in $\operatorname{WLC}\left[F_{(1,191)}=16.77 ; \beta=.28 ; p<.05\right]$. The inclusion of children in step 2 does not explain any variance in $\operatorname{WLC}\left[\Delta F_{(1,191)}=.01 ; \beta=-.00 ; p>.05\right]$. This accordingly indicates that the presence of children is not a significant predictor of WLC. However, in the third step, the two-way interaction variable $\left[\Delta F_{(1,191)}=10.03 ; \beta=7.71 ; p<.05\right]$ reveals that the presence of children significantly moderates the relationship between TASW and WLC. This results in accepting hypothesis 3.

Figure 2: Graph illustrating the moderating effect of children on TASW (main effect variable) and WLC (dependent variable)

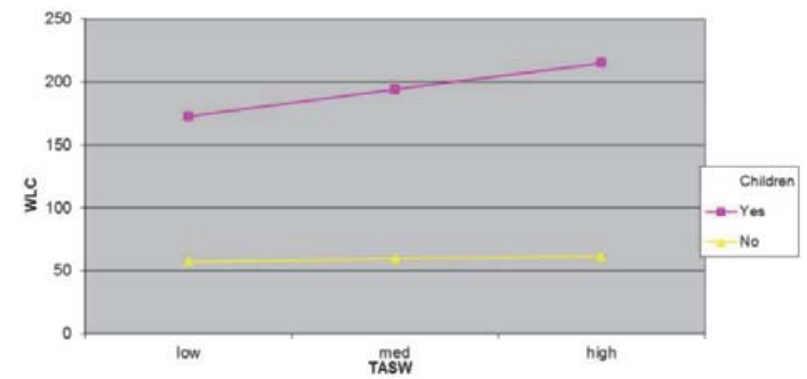

Figure 2 illustrates that, academics with children experience higher levels of WLC compared to those without children. Further, the level of WLC experienced by the academics with children increases the more they engage in TASW compared to academics without children.

\section{Discussion}

The objective of this study was to investigate the effect of family relationships on TASW and WLC experienced by academics in a higher education institution in South Africa. Specifically, the moderating roles of marital status and children were taken into consideration in investigating the relationship between TASW and WLC.

\subsection{Academics engaging in TASW}

The current study affirms hypothesis 1, that academics do indeed use ICTs after normal working hours to engage in supplemental work practices. This could be attributed to the nature of the academic profession. As aforementioned in the literature, academia is referred to as a demanding profession whereby supplemental work practices and working long hours are considered to be the norms (Currie \& Eveline, 2010; Currie et al., 2000; Houston et al., 2006; O'Laughlin \& Bischoff, 2005; Santos \& Cabral-Cardoso, 2008). This also seems to be evident in the South African academic context as the majority of respondents in the study indicated that they used their laptops to work after hours at home for between 3 and 4 hours per day. It is possible that academics within this higher education institution engage in TASW as a result of increased workloads, for example, increased teaching, research, administration and community service responsibilities (Houston et al., 2006; Kinman \& Jones, 2008; Tight, 2010; Ylijoki, 2010). Furthermore, the competitive academic environment that requires academic staff to publish research may also encourage academics to engage in TASW (Jacobs \& Winslow, 2004; Rafnsdóttir \& Heijstra, 2011). 


\subsection{Relationship between TASW and WLC}

Hypothesis 2 was accepted as the results revealed a significant and positive relationship between TASW and WLC $(r=$ $.28, p<.01)$. This accordingly indicates that, as academics engage in TASW, they also experience higher levels of WLC. This result is consistent with previous studies which have also reported a positive relationship between TASW and WLC (Boswell \& Olson-Buchanan, 2007; Fenner \& Renn, 2010; Kinman \& Jones, 2008; Messersmith, 2007).

The significant and positive relationship between TASW and WLC can be attributed to the explanations provided by various researchers (Boswell \& Olson-Buchanan, 2007; Fenner \& Renn, 2004; Parasuraman \& Simmers, 2001). Firstly, the use of ICTs to engage in work-related activities after hours at home is known to blur the traditional boundaries between work and non-work domains (Boswell \& Olson-Buchanan, 2007; Currie \& Eveline, 2010; Higgins \& Duxbury, 2005). Boswell and Olson-Buchanan (2007) explain that the use of ICTs to work after hours makes it challenging for individuals to fulfil their work and non-work role demands.

However, it should be noted that the strength of the relationship between TASW and WLC is small according to the guidelines stipulated by Cohen (1988, as cited in Pallant, 2009, p. 134). A possible explanation of this could be attributed to the fact that although academics are known to have high workload demands, they are also more likely to have control over managing their time between both domains (Fenner \& Renn, 2010; Lewis, 2010). This consequently reduces WLC, as explained by Batt and Valcour (2003). It could thus be suggested that the strength of this relationship is small as academics in this sample may have good time and boundary management skills which reduces the WLC experienced from engaging in TASW (Fenner \& Renn, 2004). A further possible explanation of the relationship between TASW and WLC being minimal could be attributed to the fact that working long hours in the academic profession is the norm, and therefore an accepted practice. This is supported by Boswell and Olson-Buchanan (2007) who assert that individuals experience less WLC if working long hours and engaging in TASW are accepted practices.

It should further be noted that the linear regression revealed that TASW is a significant predictor of WLC. However, the results reveal that TASW only shares $8 \%$ of the variability in the WLC scores. This further means that $92 \%$ of the variability in the WLC scores is accounted for by other factors. Indeed, it is possible that TASW only explains a small percentage of variance in the WLC scores due to the phenomenon being relatively new and fewer studies having been conducted in this stream of research.

\subsection{The relationship between TASW and the three forms of WLC}

Further analysis revealed that time-based and strain-based WLC are significantly and positively related to TASW. A possible reason for academics experiencing time-based WLC could be attributed to the fact that when academics engage in TASW at work, they spend more time working rather than spending that time with their family. This therefore creates time-based WLC as Boswell and Olson-Buchanan (2007) explain that it becomes challenging to fulfil the role requirements and demands of both domains. Consistent with Kinman and Jones' (2008) results, academics in the current study also experience strain-based WLC from engaging in supplemental work practices. A possible explanation for this could be that academics are psychologically unable to disengage themselves from their family when engaging in TASW at home (Messersmith, 2007). Interestingly, there was no significant relationship between TASW and behavioural-based WLC. This was unexpected as previous studies have suggested a positive relationship between TASW and behaviouralbased WLC (Fenner \& Renn, 2010). A possible explanation for the result not being positively significant could be attributed to the fact that the overall strength of the relationship between TASW and WLC is weak. It is further possible that academics do not engage in TASW as often, reducing the behavioural-based WLC that they would experience. Alternatively, as suggested previously, it is also possible that academics in this institution have good time and boundary management skills, reducing WLC, including behavioural-based WLC experienced as a result of engaging in TASW (Fenner \& Renn, 2010; Lewis, 2010).

\subsection{The effect of marital status on the relationship between TASW and WLC}

It was tested whether engaging in TASW increased or decreased the WLC experienced by married and by unmarried academics. It is evident from Figure 1 that married academics experience more WLC from engaging in TASW in comparison to unmarried academics. Hence, this suggests that the marital status of academics affects the relationship between TASW and WLC.

Consistent with previous research, the findings of this hypothesis also suggest that married individuals experience more WLC than individuals who are single (Russell et al., 2009). This is attributed to the increased responsibilities 
associated with being married. In addition, Venkatesh and Vitalari (1992) suggest that marital status also influences the extent to which individuals work at home. It can be assumed that unmarried individuals have fewer family responsibilities than married individuals. Hence, when married academics engage in TASW, they are also more likely to experience WLC as a result of more responsibilities, demanding additional time. Hence, engaging in TASW at home diminishes the work and family boundaries which generate additional strain-based, time-based and behaviour-based WLC (Batt \& Valcour, 2003; Boswell \& Olson-Buchanan, 2007; Fenner \& Renn, 2010; Messersmith, 2007). On the contrary, unmarried individuals, in general, experience less WLC from engaging in TASW as a result of fewer family responsibilities. However, this is contrary to the findings reported by Hamilton et al. (2006), who found no significant differences in the amount of WLC experienced by married and unmarried academics. Nonetheless, the results of the current study indicate that married academics experience higher levels of WLC than unmarried academics. Furthermore, married academics experience higher levels of WLC from engaging in TASW. Indeed, these findings indicate that marital status has a moderating effect on the relationship between TASW and WLC.

\subsection{The effect of children on the relationship between TASW and WLC}

It was further tested whether engaging in TASW increased or reduced the WLC experienced by academics with children compared to academics without children. Figure 2 suggests that academics with children experience more WLC from engaging in TASW than academics without children. Hence, the results indicate that the presence of children in an academic's life has a moderating effect on the relationship between TASW and WLC.

There are various reasons that could explain these findings. For example, the responsibility and role demands of academics (in particular women academics) are further known to increase with having a child or a number of children (Russell et al., 2009; Venkatesh \& Vitalari, 1992; Ward \& Wolf-Wendel, 2004). This therefore increases the WLC experienced by academics (Jones \& McKenna, 2002; Russell et al., 2009; Ward \& Wolf-Wendel, 2004). Academics with children are less likely than others to engage in TASW at home due to family responsibilities (Venkatesh \& Vitalari, 1992). Although ICTs are known to enhance work flexibility, which enables academics to spend more time with their children, research also suggests that academics constantly feel guilty for not spending enough time with their children as a result of work pressures (Ward \& Wolf-Wendel, 2004). Hence, even though academics with children engage in TASW, they experience WLC due to not being able to spend that time with their children or, as explained previously, they are unable to disengage themselves from their work (Messersmith, 2007). Thus, the finding of this hypothesis is consistent with previous research which suggests that academics with children are more likely to experience WLC from engaging in supplemental work practices due to the increased demands made by children (Jones \& McKenna, 2002; O'Laughlin \& Bischoff, 2005; Venkatesh \& Vitalari, 1992).

\section{Limitations of Current Study}

The current study had some limitations that need to be taken into consideration while interpreting the findings of the current study. A limitation of this study is that no causal relationships can be established, as the current study adopted a cross-sectional research design. Furthermore, the results of this study cannot be generalised to other institutions or populations as the study was conducted using academic staff from a particular higher education institution in South Africa. In addition, the purposive and convenience sampling methods used in the current study also limit the ability to generalise the findings to a larger population. Additionally, individual differences, such as being ambitious or committed, were not included as part of the research study. Moreover, not all variables were included as possible moderators in influencing the relationship between TASW and WLC.

\section{Recommendations for Future Studies}

It is recommended that future studies adopt a longitudinal research design to investigate the phenomenon of TASW and its relationship with WLC. Additionally, future studies should replicate the current study in other higher education institutions in South Africa. Similarly, studies could also extend their research using other professions. This will further determine whether similar results are found in other institutions and with other professions. Future studies should also adopt a random sampling method to be able to generalise the findings to a larger population. For the same reason, a larger sample size should also be used for future studies. Furthermore, future studies should also investigate the role of behavioural-based WLC from engaging in TASW as this finding was contrary to what was expected. 


\section{Recommendations to the Higher Education Institution}

Based on the current study's findings and supported by various literatures, the following recommendations are made to the institution in order to reduce the WLC experienced by academics from engaging in TASW:

\subsection{Establish clear policies pertaining to the use of ICTs after hours}

It is suggested that the institution develop clear policies and expectations about using ICTs for work-related purposes after hours. Specifically, the institution should develop policies that limit the use of ICTs after normal working hours. These policies should also thus be applied during the evenings, on weekends and holidays and also when on leave.

\subsection{Change in communication behaviours}

Top management and superiors should play a further role in restricting staff from engaging in TASW by modelling the desired behaviour themselves. For example, top management should not send out emails during holidays as this creates a perception that staff should also engage in work practices after hours.

\subsection{Create awareness of the phenomenon of TASW and provide support in managing boundaries}

The institution should provide an information session about the phenomenon of TASW to academic staff. This will create greater awareness among staff members and will encourage them to manage their work and family boundaries more effectively.

\section{Contribution of Study}

This research was conducted in a South African context, which is of significance as most previous studies pertaining to supplemental work and TASW have been conducted in USA, Canada and Finland (Boswell \& Olson-Buchanan, 2007; Duxbury et al., 1996; Fenner \& Renn, 2004; Fenner \& Renn, 2010). The results of this study have therefore contributed to the existing field of literature relating specifically to the academic context and TASW. This is valuable as TASW is an emerging field of research that has not been studied extensively, specifically in South Africa.

The current study used Fenner and Renn's (2010) TASW scale in a South Africa context using academics in a higher education institution. However, as previously explained, Fenner and Renn (2010) suggested that their TASW scale be assessed using a different population.

This study further questions the work flexibility enabled by ICTs and the role that they play in encouraging academics to engage in TASW. Hence, ICTs enhance work flexibility and WLB, but also however encourage academics to use ICTs after hours for work-related purposes, which consequently results in WLC. It is thus anticipated that the results obtained from this study will add value to the existing field of literature relating to the academic profession, TASW and WLC.

\section{Conclusion}

This research revealed that academics do engage in TASW and consequently also experience WLC. In particular, academics experience time-based and strain-based WLC. While researchers agree that ICTs play a major role in enhancing WLB, there is also agreement that the same ICTs have also contributed negatively by blurring the traditional boundaries between work and family life. This is also evident when academics continue work even after regular working hours. Furthermore, marital status and the presence of children significantly moderate the relationship between TASW and WLC. Family relationships therefore play a vital role in influencing the extent to which academics engage in TASW and consequently experience WLC. These findings make it extremely necessary for academics and for the higher education institution to understand the implications of engaging in TASW. It is suggested that academics and the higher education institution take into account the proposed recommendations in order to reduce the negative consequences of engaging in TASW.

\section{References}

Araújo, E. R. (2008). Technology, Gender and Time: A Contribution to the Debate. Gender, Work and Organization, 15(5), 276-503.

Batt, R., \& Valcour, P. M. (2003). Human Resource Practices as Predictors of Work-Family Outcomes and Employee Turnover. Industrial Relations, 42(2), 189-220.

Bernardi, R. A. (1994). Validating Research Results when Cronbach's Alpha is Below .70: A Methodological Procedure. Educational and Psychological 
Measurement, 54(3), 766-775. doi:10.1177/0013164494054003023.

Boswell, W. R., \& Olson-Buchanan, J. B. (2007). The Use of Communication Technologies After Hours: The Role of Work Attitudes and Work-Life Conflict. Journal of Management, 33(4), 592-610. doi:10.1177/0149206307302552.

Brough, P, O'Driscoll, M. P., \& Kalliath, T. J. (2005). Work-family conflict and facilitation: Achieving work-family balance. Advances in Organisational Psychology (pp. 73-92). Retrieved from http://search.informit.com.au/documentSummary; dn =385528529326447; res=E-LIBRARY.

Carlson, D. S., Grzywacz, J. G., \& Zivnuska, S. (2009). Is work-family balance more than conflict and enrichment? Human Relations, 62(10), 1459-1486. doi:10.1177/0018726709336500.

Carlson, D. S., Kacmar, K. M., \& Williams, L. J. (2000). Construction and Initial Validation of a Multidimensional Measure of Work - Family Conflict. Journal of Vocational Behavior, 56, 249-276. doi:10.1006/jvbe.1999.1713

Clark, S. C. (2001). Work Cultures and Work/Family Balance. Journal of Vocational Behavior, 58(3), 348-365. doi:10.1006/jvbe.2000.1759.

Currie, J., \& Eveline, J. (2010). E-technology and work/life balance for academics with young children. Higher Education, 62(4), 533-550. doi:10.1007/s10734-010-9404-9.

Currie, J., Harris, P., \& Thiele, B. (2000). Sacrifices in Greedy Universities: Are they gendered? Gender and Education, 12(3), 269-291.

Duxbury, L. E., Higgins, C., \& Thomas, D. (1996). Work and Family Environments and the Adoption of Computer-Supported Supplemental Work-at-Home. Journal of Vocational Behavior, 23(49), 1-23.

Duxbury, L., Higgins, C., \& Lee, C. (1994). Work-Family Conflict: A Comparison by Gender, Family Type, and Perceived Control. Journal of Family Issues, 15(3), 449-466. doi:10.1177/019251394015003006.

Fenner, G. H., \& Renn, R. W. (2010). Technology-assisted supplemental work and work-to-family conflict: The role of instrumentality beliefs, organizational expectations and time management. Human Relations, 63(1), 63-82. doi:10.1177/0018726709351064.

Fenner, G. H., \& Renn, R. W. (2004). Technology-assisted supplemental work: Construct definition and a research framework. Human Resource Management, 43(2-3), 179-200. doi:10.1002/hrm.20014.

Greenhaus, J. H., Allen, T. D., \& Spector, P. E. (2006). Health consequences of work-family conflict: The dark side of work-family interface. Research in Occupational Stress and Well Being, 5, 61-98. doi:10.1016/S1479-3555(05)05002-X.

Greenhaus, J. H., \& Beutell, N. J. (1985). Sources of Conflict between Work and Family Roles. The Academy of Management Review, $10(1), 76-88$.

Gornall, L., \& Salisbury, J. (2012). Compulsive Working, 'Hyperprofessionality' and the Unseen Pleasures of Academic Work. Higher Education Quarterly, 66(2), 135-154. doi:10.1111/j.1468-2273.2012.00512.x.

Hamilton, E. A., Gordon, J. R., \& Whelan-Berry, K. S. (2011). Understanding the work-life conflict of never-married women without children. Women in Management Review, 21(5), 393-415. doi:10.1108/09649420610676208.

Harmer, B., Pauleen, D. J., \& Schroeder, A. (2008). Cause or Cure: Technologies and Work-Life Balance. Informational Conference on Information Systems (ICIS) (pp. 1-15). Paris.

Heijstra, T. M., \& Rafnsdottir, G. L. (2010). The internet and academics' workload and work-family balance. Internet and Higher Education, 13(3), 158-163. doi:10.1016/j.iheduc.2010.03.004.

Hewlett, A., \& Luce, C. B. (2006). Extreme jobs: The dangerous allure of the 70-hour workweek. Harvard Business Review, (December), 49-59.

Houston, D., Meyer, L. H., \& Paewai, S. (2006). Academic staff workloads and job satisfaction: Expectations and values in academe. Journal of Higher Education Policy and Management, 28(1), 17-30. doi:10.1080/13600800500283734.

Jacobs, J. A., \& Winslow, S. E. (2004). Overworked Faculty: Job Stresses and Family Demands. The ANNALS of the American Academy of Political and Social Science, 596, 104-129. doi:10.1177/0002716204268185.

Jones, W. M., \& Mckenna, J. (2002). Women and work-home conflict: a dual paradigm approach. Health Education, 102(5), $249-259$. doi:10.1108/09654280210444128.

Kinman, G., \& Jones, F. (2008). A Life Beyond Work? Job Demands, Work-Life Balance, and Wellbeing in UK Academics. Journal of Human Behavior in the Social Environment, 17(1-2), 41-60. doi:10.1080/10911350802165478.

Messersmith, J. (2007). Managing work-life conflict among information technology workers. Human Resource Management, 46(3), 429-451. doi:10.1002/hrm.20172.

O'Laughlin, E. M., \& Bischoff, L. G. (2005). Balancing Parenthood and Academia: Work/Family Stress as Influenced by Gender and Tenure Status. Journal of Family Issues, 26(1), 79-106. doi:10.1177/0192513X04265942.

Pallant, J. (2009). SPSS Survival Manual: A step by step guide to data analysis using SPSS (4th ed.). China: Allen \& Unwin.

Parasuraman, S., \& Simmers, C. A. (2001). Type of employment, work-family conflict and well-being: a comparative study. Journal of Organizational Behavior, 22, 551-568. doi:10.1002/job.102.

Rafnsdóttir, G. L., \& Heijstra, T. M. (2011). Balancing Work-family Life in Academia: The Power of Time. Gender, Work and Organization, 1-14. doi:10.1111/j.1468-0432.2011.00571.x.

Russell, H., Connell, P. J. O., \& McGinnity, F. (2009). The Impact of Flexible Working Arrangements on Work-life Conflict and Work Pressure in Ireland. Gender, Work and Organization, 16(1), 73-97.

Santos, G. G., \& Cabral-Cardoso, C. (2005). Work-family culture in academia: a gendered view of work-family conflict and coping strategies. Gender in Management: An International journal, 23(6), 442-457. doi:10.1108/17542410810897553.

Skinner, N., \& Pocock, B. (2008). Work-life conflict: Is work time or work overload more important? Asia Pacific Journal of Human Resources, 46(3), 303315. doi:10.1177/1038411108095761.

Tight, M. (2010). The Golden Age of Academe: Myth or Memory? British Journal of Educational Studies, 58(1), 105-116. doi:10.1080/00071000903516502.

Valcour, M. (2007). Work-Based Resources as Moderators of the Relationship Between Work Hours and Satisfaction With Work - Family Balance. Journal of Applied Psychology, 92(6), 1512-1523. doi:10.1037/0021-9010.92.6.1512.

Venkatesh, A, \& Vitalari, N. P. (1992). An Emerging Distributed Work Arrangement: An Investigation of Computer-Based Supplemental Work at Home. Management Science, 38(12), 1687-1706.

Ward, K., \& Wolf-Wendel, L. (2004). Academic Motherhood: Managing Complex Roles in Research Universities. The Review of Higher Education, 27(2), $233-257$.

Westenholz, A. (2006). Identity, Times and Work. Time \& Society, 15(1), 33-55. doi:10.1177/0961463X06061349.

Ylijoki, O. H., \& Mantyla, H. (2003). Conflicting Time Perspectives in Academic Work. Time \& Society, 12(1), 55-78. doi:10.1177/0961463X03012001364.

Ylijoki, O. H. (2010). Future orientations in episodic labour: Short-term academics as a case in point. Time Society, 19(3), 365-386. doi:10.1177/0961463X10356220. 